Editorial Vol. 9, No. 2, 2019

\title{
ICL2018 Highlights by iJEP
}

\author{
https://doi.org/10.3991/ijep.v9i2.10670
}

The theme of ICL2018 Conference was "Teaching and Learning in a Digital World". The event was held in Kos, Greece September 25-28, 2018 (http:/www.iclconference.org/icl2018/). ICL2018 was the 21st International Conference on Interactive Collaborative Learning and 47th IGIP International Conference on Engineering Pedagogy. ICL2018 was organized in cooperation with Aristotle University of Thessaloniki (AUTH), International Association of Online Engineering (IAOE) and International Society for Engineering Pedagogy (IGIP). ICL2018 hosted the 1st ICL International Student Competition on Learning Technologies. The aims of the competition were:

- To provide an opportunity for students to participate in the conference and demonstrate their Learning Technologies design and development skills under an International competition process;

- To provide an opportunity for students who are Learning Technologies developers to peer-assess and peer-evaluate their technologies;

- To provide ICL attendees with engaging and fresh Learning Technologies, that should demonstrate their functionality and impact in the Learning Technologies scene.

At the ICL2018 the 1st IGIP International Award for Games in Engineering Education (GinEE) was conferred on two outstanding contributions.

The program committee and the reviewers had to review 445 papers. Finally 176 papers were presented in 38 parallel sessions. The papers were divided into sessions with full papers, short papers and works in progress. Since, traditionally, ICL2018 is especially directed to close the gap between pure academic research and applications as well as to experiences in the daily educational processes, several special sessions organized by prominent researchers and educators discussed emerging fields in Engineering Education, such as:

- Collaborative learning

- Lifelong learning

- Adaptive and intuitive environments

- Ubiquitous learning environments

- Semantic metadata for e-learning

- Mobile learning environments applications

- Computer aided language learning (CALL)

- Platforms and authoring tools

- Educational MashUps

- Knowledge management and learning

- Educational Virtual Environments 
- Standards and style-guides

- Remote and virtual laboratories

- Evaluation and outcomes assessment

- New learning models and applications

- Research in Engineering Pedagogy

- Engineering Pedagogy Education

- Learning culture \& diversity

- Ethics and Engineering Education

- Technical Teacher Training

- Academic-industry partnerships

- Impact of globalization

- K-12 and pre-college programs

- Role of public policy in engineering education

- Women in engineering careers

- Flipped classrooms

- Game-based learning

- Project based learning

- New trends in graduate education

- Cost-effectiveness

- Real world experiences

- Pilot projects / Products / Applications

There were eight Special Sessions:

- "Entrepreneurship in Engineering Education" (EiEE'18)

- "Multicultural Diversity in Education and Science"

- "Talking about Teaching 2018" (TaT'18)

- "Engineering Pedagogy Terminology"

- "Digital Technology in Sports" (DiTeS)

- "Advancements in Engineering Education and Technology Research" (AEETR)

- "Tangible and Intangible Cultural Heritage digitization and preservation in modern era" (TICHE-DiPre)

- "Using Learning Analytics to improve the cognitive and social aspects of learning" (ANALYSE)

This year's theme of the conference was "Teaching and Learning in a Digital World".

Again outstanding scientists from around the world accepted the invitation for keynote speeches:

- Stephanie Farrell, Professor and Founding Chair of Experiential Engineering Education at Rowan University (USA) - 2018-19 President of the American Society for Engineering Education. Speech title: Strategies for Building Inclusive Classrooms in Engineering. 
- Demetrios Sampson. PhD(ElectEng) (Essex), PgDip (Essex), BEng/MEng(Elec) (DUTH), CEng - Golden Core Member, IEEE Computer Society - Professor, Digital Systems for Learning and Education, University of Piraeus, Greece. Speech title: Educational Data Analytics for Personalized Learning in Online Education.

- Rovani Sigamoney, UNESCO Engineering Programme. Speech title: UNESCO - Engineering the Sustainable Development Goals.

In addition, three invited speeches has been given by

- Hans J. Hoyer, IFEES, United States of America. Speech title: The work of IFEES and GEDC towards a new Quality in Engineering Education.

- David Guralnick, Kaleidoscope Learning, United States of America. Speech title: Creative Approaches to Online Learning Design.

- Hanno Paul Hortsch, TU Dresden. Speech title: Overview of ICL conferences.

Furthermore, five very interesting workshops and one tutorial have been organized:

- Tutorial titled "Improving Practical Communication Skills through Participation in Collaborative English Workshops" by Edward Pearse Sarich (Shizuoka University of Art and Culture, Japan); Mark Daniel Sheehan (Hannan University, Japan), and Jack Ryan (Shizuoka University of Art and Culture, Japan).

- Workshop titled "Evaluation of Experimental Activities by Diana Urbano and Maria Teresa Restivo" (University of Porto, Portugal).

- Workshop titled "Machine Learning \& Interactive Collaborative Learning" by Panayotis Tzinis and Irene Tsakiridou (Google Developer Experts).

- Workshop titled "Teaching and Learning Electrical Engineering and Computer Science in High School with a STEM Approach" by Arturo Javier Miguel-de-Priego (Academia de Ingeniería y Ciencia Escolar, Perú).

- Workshop titled "Introduction to BLE System Design Using PSoC® 6 MCUs" by Patrick Kane (Cypress).

With this issue, the iJEP Journal likes to take the opportunity to present a selection of the engineering education related research and best practices that were presented at ICL2018. Authors whose papers could be of great interest for the readers of the iJEP Journal were invited to submit an extended and/or updated version of their work.

The lively discussions during the sessions as well during the social functions of the conference covered all the new trends in engineering education as well as traditional issues educators and researchers have been facing for many years. Virtual labs, gamebased learning and quality in engineering education were the topics that got the lion's 
Editorial-ICL2018 Highlights by iJEP

share in these discussions. ICL2018 really represents a significant milestone in the history of engineering education!

$\begin{array}{llll}\text { Michael E. Auer } & \text { Thrasyvoulos } & \text { Matthias C. Utesch } & \text { Matthias Gottlieb } \\ & \text { Tsiatsos } & & \\ \text { Carinthia Tech } & \text { Aristotle } & \text { Technical } & \text { Technical } \\ \text { Institute, Austria } & \text { University of } & \text { University } & \text { University of } \\ & \begin{array}{l}\text { Thessaloniki, } \\ \text { Greece }\end{array} & \text { Munich, Germany } & \text { Munich, Germany }\end{array}$

